\title{
A Semi-Analytical Solution for Steady Infiltration in Unsaturated Fractured Rock
}

\author{
Clifford K. Ho \\ Sandia National Laboratories \\ P.O. Box 5800, MS-0735 \\ Albuquerque, NM 87185-0735 \\ (505) 844-2384 \\ ckho@sandia.gov
}

\begin{abstract}
A semi-analytical solution is developed for one-dimensional steady infiltration in unsaturated fractured rock. The differential form of the mass conservation equation is integrated to yield an analytical expression relating elevation to a function of capillary pressure and relative permeability of the fracture and rock matrix. Constitutive relationships for unsaturated flow in this analysis are taken from van Genuchten [1980] and Mualem [1976], but alternative relations can also be implemented in the integral solution. Expressions are presented for the liquid saturations and pore velocities in the fracture, matrix, and effective continuum materials as a function of capillary pressure and elevation. Results of the analytical solution are applied to examples of infiltration in fractured rock consisting of both homogeneous and composite (layered) domains. The analytical results are also compared to numerical simulations to demonstrate the use of the analytical solution as a benchmarking tool to address computational issues such as grid refinement.
\end{abstract}

\section{Introduction}

Unsaturated flow in fractured rock can be an important process in applications ranging from contaminant remediation to nuclear waste management. A number of different conceptual models have been developed to represent the processes and features of this system [Pruess and 


\section{DISCLAIMER}

This report was prepared as an account of work sponsored by an agency of the United States Government. Neither the United States Government nor any agency thereof, nor any of their employees, make any warranty, express or implied, or assumes any legal liability or responsibility for the accuracy, completeness, or usefulness of any information, apparatus, product, or process disclosed, or represents that its use would not infringe privately owned rights. Reference herein to any specific commercial product, process, or service by trade name, trademark, manufacturer, or otherwise does not necessarily constitute or imply its endorsement, recommendation, or favoring by the United States Government or any agency thereof. The views and opinions of authors expressed herein do not necessarily state or reflect those of the United States Government or any agency thereof. 


\section{DISCLAIMER}

Portions of this document may be illegible in electronic image products. Images are produced from the best available original document. 
Narasimhan, 1985; Peters and Klavetter, 1988; Ho et al., 1995; Liu et al., 1998; Doughty, 1999; and Pruess et al., 1999]. However, the large disparity between the hydrologic parameters and processes of the fractures and rock matrix pose challenges in numerical models that attempt to simulate discrete flow in the two media. In some applications, the net infiltration through the fractured rock is either extremely slow, or the properties of the fractured media are such that the unsaturated flow processes are dominated by the rock matrix. In these particular cases, the liquid may exist in local equilibrium between the fracture and rock matrix (i.e., no net exchange between the two media), and an effective (or equivalent) continuum model (ECM) can be employed.

Several previous investigators have developed a mathematical model for unsaturated flow in fractured rock assuming pressure equilibrium between the fractures and rock matrix for isothermal flow [Klavetter and Peters, 1986 and Peters and Klavetter, 1988]. An effective continuum formulation was also developed for non-isothermal multiphase processes assuming local thermodynamic equilibrium between the fractures and rock matrix [Pruess et al., 1985]. Equations for the effective unsaturated conductivity and saturation were developed as functions of the intrinsic parameters for the fractures and rock matrix. The ECM has subsequently been evaluated and implemented in hydrological and thermal-hydrological numerical simulations, including applications for the potential nuclear waste repository at Yucca Mountain [Tsang and Pruess, 1987; Pruess et al., 1990; Buscheck and Nitao, 1993; Ho et al., 1995; Eaton et al., 1996; and Wu et al., 1999].

The purpose of this paper is to present a one-dimensional, steady-state analytical solution for the ECM subject to isothermal infiltration in fractured rock. The solution is an extension of the results presented in Ho et al. [1995], whose solution was limited to a single, homogeneous 
fractured media; the current solution is applied to composite (layered) media as well. In addition, an efficient and accurate forward-marching scheme is developed for the resulting analytical expressions. Analytical methods have been developed previously for infiltration in single-porosity media (i.e., soils) [Gardner, 1958; Warrick and Yeh, 1990; Parlange et al., 1997; and Rockhold et al., 1997], but application to layered fractured media has not been reported. The derivation of the analytical solution is presented next, followed by applications of the solution to infiltration in both homogeneous and composite fractured media. Comparisons with numerical simulations are presented and discussed, and important assumptions regarding the ECM solution are summarized.

\section{Mathematical Model}

The one-dimensional, steady-state equation for conservation of mass of liquid flow in an unsaturated differential control volume can be written as follows:

$$
\frac{d}{d z}(\rho u)=0
$$

where $z$ is the vertical coordinate (positive upwards) (m), $\rho$ is the liquid density $\left(1000 \mathrm{~kg} / \mathrm{m}^{3}\right.$ for water at $\left.20^{\circ} \mathrm{C}\right)$, and $u$ is the vertical bulk velocity $(\mathrm{m} / \mathrm{s})$. Substituting Darcy's Law for the velocity and assuming incompressible vertical flow yields the following expression:

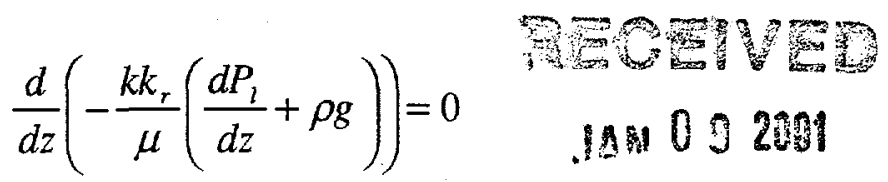

$$
\begin{aligned}
& \text { ( STI }
\end{aligned}
$$

where $k$ is intrinsic permeability $\left(\mathrm{m}^{2}\right), k_{r}$ is relative permeability $(-), \mu$ is dynamic viscosity of the liquid $\left(1 \times 10^{-3} \mathrm{~N}-\mathrm{s} / \mathrm{m}^{2}\right.$ for water at $\left.20^{\circ} \mathrm{C}\right), P_{l}$ is liquid pressure $(\mathrm{Pa})$, and $g$ is gravity $\left(9.81 \mathrm{~m}^{2} / \mathrm{s}\right)$. 
The liquid pressure can be expressed as a function of the capillary pressure, $P_{c}$, and the gas pressure, $P_{g}$ :

$$
P_{l}=P_{g}-P_{c}
$$

In this analysis, the gas pressure is assumed constant, and (2) can be written as follows:

$$
\frac{d}{d z}\left(\frac{k k_{r}}{\mu}\left(\frac{d P_{c}}{d z}-\rho g\right)\right)=0
$$

Integrating (4) with respect to $z$ yields the following:

$$
\frac{k k_{r}}{\mu}\left(\frac{d P_{C}}{d z}-\rho g\right)=c_{1}=-q
$$

where $c_{1}$ is a constant of integration. The constant of integration is determined by setting the left-hand side of (5) equal to a known or prescribed infiltration rate, $q$ (i.e., the Darcy velocity). The imposed downward infiltration rate is negative since the velocity defined by the left-hand side of (5) is positive upwards. Equation (5) can be rearranged and integrated with respect to both the vertical coordinate, $z$, and capillary pressure, $P_{c}$, to yield the following:

$$
z_{2}=z_{1}+\int_{P_{c}\left(z_{1}\right)}^{P_{c}\left(z_{2}\right)} \frac{d P_{c}}{\rho g-\frac{\mu q}{k k_{r}}}
$$

A boundary condition that provides the capillary pressure at $z_{1}$ is required for (6). If $z_{1}$ is set equal to the elevation of the water table, $P_{c}\left(z_{1}\right)$ can be set equal to zero, and (6) can be solved for 
the elevation, $z_{2}$, of any other capillary pressure, $P_{c}\left(z_{2}\right)$. To obtain a distribution of elevation vs. capillary pressure data, Equation (6) is solved using a forward-marching method (in the upward direction) by setting $z_{i}=z_{1}$ and $z_{i+1}=z_{2}$, where $i=1,2, \ldots n$ ( $n=$ desired number of data points). Thus, the integrand is discretized into $n$ points between the integration limits, $P_{c}\left(z_{1}\right)$ and $P_{c}\left(z_{2}\right)$. This forward-marching solution also tends to provide more accurate integral solutions because the integration limits span smaller intervals, which is desired when using numerical quadrature or commercial applications such as Mathcad ${ }^{\circledR}$ to solve (6). Equation (6) can also be generalized for composite media (with multiple layers) by marching forward from $P_{c}\left(z_{1}\right)$ to $P_{c}\left(z_{n}\right)$ through each layer, where the material properties in (6) are taken from the appropriate layer, say $\Omega$, where $\Omega=1,2, \ldots m$ ( $m=$ total number of layers). When the interface of two layers is reached during the forward-marching process, the capillary pressure of the overlying layer is set equal to the capillary pressure of the underlying layer at the interface. Thus, the capillary pressure and elevation that are determined at each interface prescribe new boundary conditions for the integral solution of the overlying layer. These generalizations can be incorporated into (6) and rewritten as follows:

$$
z_{i+1}^{(\Omega)}=z_{i}^{(\Omega)}+\int_{P_{c}^{(\Omega)}\left(z_{i}\right)}^{P_{c}^{(\Omega)}\left(z_{i+1}\right)} \frac{d P_{c}^{(\Omega)}}{\rho g-\frac{\mu q}{\left(k k_{r}\right)^{(\Omega)}}}
$$

where $\Omega$ denotes each layer in succession starting from the bottom $(\Omega=1,2, \ldots m)$. The following boundary conditions are applied at each layer interface:

$$
z_{i}^{(\Omega+1)}=z_{i}^{(\Omega)}
$$




$$
P_{c}\left(z_{i}^{(\Omega+1)}\right)=P_{c}\left(z_{i}^{(\Omega)}\right)
$$

In (7a), the relative permeability, $k_{r}$, is a function of liquid saturation and, therefore, capillary pressure. As shown in Ho et al. [1995], the van Genuchten [1980] and Mualem [1976] equations describing liquid saturation and relative permeability as a function of capillary pressure can be used to obtain these relations:

$$
\begin{aligned}
& k_{r, j}=\frac{\left[1-\left(\alpha_{j} P_{c}\right)^{\beta_{j}-1}\left(1+\left(\alpha_{j} P_{c}\right)^{\beta_{j}}\right)^{-\lambda_{j}}\right]^{2}}{\left[1+\left(\alpha_{j} P_{c}\right)^{\beta_{j}}\right]^{\lambda_{j} / 2}} \\
& S_{j}=S_{r, j}+\left(S_{s, j}-S_{r, j}\right)\left[1+\left(\alpha_{j} P_{c}\right)^{\beta_{j}}\right]^{-\lambda_{j}}
\end{aligned}
$$

where $\alpha$ and $\beta$ are fitting parameters (using nomenclature consistent with Peters and Klavetter, [1988]), $\lambda$ is equal to $1-1 / \beta, S_{r}$ is the residual saturation, $S_{s}$ is the maximum saturation, and the subscript $j$ denotes either the fracture or matrix material. Other constitutive relationships between liquid relative permeability, liquid saturation, and capillary pressure can also be used in the integral solution. Exponential functions for the constitutive relations [Gardner, 1958] can be employed to yield an exact solution to (7), but, in general, (7) can be solved using numerical quadrature for more complex integrand functions (we use Mathcad ${ }^{\circledR} 7$, which employs a Romberg integration scheme, to solve the analytical expressions in this analysis).

If the domain were comprised of a single porosity material, (8) could be used directly in (7) to determine a solution. Equation (9) could then be used to determine the saturation distribution. 
However, the effective continuum considered in this analysis is comprised of both fractures and rock matrix. The liquid saturation, and hence relative permeability, can be drastically different between the two media. Therefore, the relative permeability in (7) is a combination of the fracture and matrix relative permeabilities given in (8). The intrinsic permeability, $k$, is also a combination of fracture and matrix intrinsic permeabilities. The resulting volume-averaged product of the intrinsic permeability and the relative permeability in (7) is expressed as follows [Peters and Klavetter, 1988]:

$$
k k_{r}=k_{f} k_{r, f} \phi_{f}+k_{m} k_{r, m}\left(1-\phi_{f}\right)
$$

where the subscripts $f$ and $m$ denote the fracture and matrix materials. Equations (8) and (10) can be used in (7) to determine the capillary pressure distribution. Once the capillary pressure distribution is determined, the individual fracture and matrix saturations can be solved using (9). The fracture and matrix saturations are then used in the following equation to determine the effective continuum saturation [Peters and Klavetter, 1988]:

$$
S=\frac{S_{f} \phi_{f}+S_{m}\left(1-\phi_{f}\right) \phi_{m}}{\phi_{f}+\left(1-\phi_{f}\right) \phi_{m}}
$$

Equations (7)-(11) can be used to determine the saturation distribution resulting from onedimensional infiltration into a layered, unsaturated domain consisting of both fracture and matrix materials. In addition, although the total Darcy velocity, $q$, is assumed constant, the individual pore velocities in the fractures and rock matrix can be determined by dividing the Darcy velocity 
in (5) for each medium by the area available for flow (note that the intrinsic fracture porosity is assumed equal to one in (12a)):

$$
\begin{gathered}
v_{f}=-\frac{k_{f} k_{r, f}}{\mu\left(S_{f}-S_{r, f}\right)}\left(\frac{d P_{c}}{d z}-\rho g\right) \\
v_{m}=-\frac{k_{m} k_{r, m}}{\mu \phi_{m}\left(S_{m}-S_{r, m}\right)}\left(\frac{d P_{c}}{d z}-\rho g\right) \\
\frac{d P_{c}}{d z}=\frac{P_{c}\left(z_{i+1}\right)-P_{c}\left(z_{i}\right)}{z_{i+1}-z_{i}}
\end{gathered}
$$

where

It is worth noting that, based on mass conservation, the sum of the area-weighted Darcy velocities for the fracture and matrix equals the total Darcy velocity, $q$, at any point in the domain:

$$
q=\left[v_{f}\left(S_{f}-S_{r, f}\right)\right] \phi_{f}+\left[v_{m} \phi_{m}\left(S_{m}-S_{r, m}\right)\right]\left(1-\phi_{f}\right)
$$

where the two terms in the brackets on the right-had side of (13) represent the Darcy velocity in the fracture and matrix, respectively.

$\dagger$ Note that the fracture porosity in $(10)$ and (11) is defined relative to the total volume $\left(\mathrm{m}^{3}\right.$ pore in fracture $/ \mathrm{m}^{3}$ total), while the matrix porosity is defined relative to the matrix volume $\left(\mathrm{m}^{3}\right.$ pore in matrix $/ \mathrm{m}^{3}$ matrix). The intrinsic fracture porosity $\left(\mathrm{m}^{3}\right.$ of pore in fracture $/ \mathrm{m}^{3}$ fracture) is assumed equal to one. 


\section{Results and Discussion}

The analytical solutions developed in the previous section are applied to examples of both homogeneous and layered fractured media. Table 1 presents a hypothetical set of fracture and matrix material properties that are used in the examples.

Table 1. Hypothetical Material Properties for Fractured Rock [based on Klavetter and Peters, 1986]

\begin{tabular}{lccc}
\hline & Fracture & Matrix 1 & Matrix 2 \\
\hline Permeability, $k\left(\mathrm{~m}^{2}\right)$ & $1.7 \times 10^{-12}$ & $1.9 \times 10^{-18}$ & $4.5 \times 10^{-16}$ \\
Porosity, $\phi$ & $1.8 \times 10^{-4}$ & 0.11 & 0.24 \\
van Genuchten $\alpha(1 / \mathrm{Pa})$ & $1.31 \times 10^{-4}$ & $5.78 \times 10^{-7}$ & $1.44 \times 10^{-6}$ \\
van Genuchten $\beta$ & 4.23 & 1.80 & 2.64 \\
Residual Saturation, $S_{r}$ & 0.04 & 0.08 & 0.066 \\
Full Saturation, $S_{s}$ & 1.0 & 1.0 & 1.0 \\
\hline
\end{tabular}

Note: In Section 3.1, the fracture and matrix 1 properties are used. In Section 3.2, the fracture properties are applied to all layers $(\Omega=1,2,3)$. The matrix 1 properties are applied to layers 1 and 3 $(\Omega=1,3)$, and the matrix 2 properties are applied to layer $2(\Omega=2)$.

\subsection{Application to a Homogeneous Fractured Domain}

The solutions to (7)-(12) are demonstrated for a simple example of infiltration in a onedimensional, unsaturated, fractured domain. The domain is assumed to extend 530 meters upward from the water table at $z=0$. The capillary pressure at the water table is assumed to be zero, and a steady infiltration rate of $0.1 \mathrm{~mm} / \mathrm{year}$ is applied to the top of the domain. Material properties for the fractures and matrix are taken from Table 1. Equations (7)-(11) yield the effective continuum saturation distribution, which is plotted in Figure 1. Equation (7) uses a total of $n=1032$ uniformly spaced points (each separated by $1000 \mathrm{~Pa}$ ) to span the prescribed domain in the forward-marching integration scheme. At $i=1032$, the capillary pressure is $1.032 \times 10^{6} \mathrm{~Pa}$ and the elevation is $532 \mathrm{~m}$. 
The results of a numerical simulation using TOUGH2 [Pruess, 1991] are also shown in Figure 1. The TOUGH 2 code has been used extensively in the hydrologic community, and it has been tested in numerous applications [Pruess, 1998]. The TOUGH2 model used in this analysis employs the ECM formulation of Peters and Klavetter [1988] using three different discretizations: (1) 10 uniform elements each 53 meters high; (2) 20 uniform elements each 26.5 meters high; and (3) 100 uniform elements each 5.3 meters high. Results of both the analytical and numerical solutions show a monotonic decrease in effective continuum liquid saturation with increasing elevation. Although not shown, (9) yields a matrix liquid saturation that closely matches the effective saturation, but the fracture saturation quickly decreases from a value near one at the water table to a value close to the residual saturation a few meters above the water table. Because the liquid is assumed to be in pressure equilibrium between the fractures and rock matrix, the majority of the liquid resides in the matrix, which sustains much higher liquid saturations than the fractures for a given capillary pressure.

The results of the TOUGH2 model are seen to converge to the analytical solution as the number of elements increase. At locations where the saturation changes rapidly with elevation, the numerical simulations with fewer elements yield errors of several percent. This example illustrates the usefulness of the analytical solution as a potential benchmark to ensure adequate grid refinement for applicable ECM numerical simulations. Additional computational issues such as the appropriate use of weighting schemes can also be addressed [Ho et al., 1995].

Figure 2 shows the analytical distribution of pore velocities calculated from (12) for the fractures and rock matrix (the version of TOUGH2 used in this analysis did not output individual pore velocities, so numerical results are not presented). Near the water table, the pore velocity of the fractures is large, reaching approximately $1000 \mathrm{~mm} /$ year one meter above the water table. 
Above an elevation of one meter, the pore velocity in the fractures decreases rapidly. The pore velocity in the matrix increases rapidly with elevation about a meter above the water table due to the rapidly decreasing liquid saturation at that location. However, above one meter, the matrix pore velocity stabilizes near $1 \mathrm{~mm} /$ year. The pore velocities can be important for predicting groundwater travel times and the fate and transport of contaminants and other solutes in unsaturated fractured rock.

\subsection{Application to a Composite Fractured Domain}

The general solution in (7) is applied to a composite domain consisting of three layers of fractured rock. A steady infiltration rate of $0.1 \mathrm{~mm} /$ year is applied to the top of the composite domain. The first layer uses properties of matrix 1 in Table 1 , and it extends from the water table to an elevation of $212 \mathrm{~m}$. The second layer uses properties of matrix 2 in Table 1 and extends from $212 \mathrm{~m}$ to $318 \mathrm{~m}$. The third layer is identical to the first layer and extends from 318 $\mathrm{m}$ to $530 \mathrm{~m}$. In all three layers, the same hypothetical fracture properties are used as given in Table 1.

Figure 3 shows the effective liquid saturation distribution for the composite domain. Results from a TOUGH2 numerical simulation using 100 uniform elements are also shown for comparison. In the first layer, the saturation decreases with increasing elevation as discussed in the previous example. At the interface of the first and second layers $(z=212 \mathrm{~m})$, the liquid saturation abruptly decreases due to the larger permeability and smaller capillary suction of matrix 2 in the second layer. At the interface of the second and third layers $(z=318 \mathrm{~m})$, the liquid saturation abruptly increases to accommodate the lower permeability and higher capillary

pressure in the third layer, which consists of the matrix 1 properties. The results of the TOUGH2 simulations are nearly identical to the analytical solution. 
Figure 4 shows the analytical pore velocity distribution in the fracture and matrix for all three layers. Throughout most of the domain, the pore velocity is larger in the matrix due to the small relative permeability (low liquid saturation) throughout most of the fractures. Only near the water table is the fracture pore velocity significant. If the infiltration were larger, say, near the saturated conductivity of the matrix, the velocities in the fractures would be significantly larger as the saturation and, hence, relative permeability increased in the fractures.

The pore velocity in the fractures and matrix in layer 1 behaves similarly to the homogeneous example shown in Figure 2. In the second layer, the fracture pore velocity drops abruptly and then continues to decrease with elevation while the matrix pore velocity increases slightly. In the third layer, the fracture pore velocity increases slightly with elevation, and the matrix pore velocity decreases slightly. This behavior is a result of the different values of relative permeability, capillary pressure, and properties of the fracture and matrix materials in the different layers as derived in (12).

\subsection{Assumptions}

It is useful to review the assumptions used to develop the analytical solutions in (7)-(12) to determine the applicability of the solutions to various applications involving infiltration in fractured rock. We assume steady-state, one-dimensional, isothermal, incompressible, vertical liquid flow, and the infiltration and gas pressure are assumed constant. Each layer of a composite fractured media is assumed to be homogenous so that all properties within a layer are constant. Finally, and most importantly, the liquid is assumed to be in equilibrium between the fracture and rock matrix so that no net exchange occurs between the two media; therefore, flow can be modeled through a single effective continuum as derived in Peters and Klavetter [1988]. For conditions where significant fracture/matrix interaction occurs, a dual- or multi-continuum 
method is recommended (see Pruess and Narasimhan [1985]; Ho [1997]; Liu et al. [1998]; and Doughty [1999] for descriptions of alternative conceptual models).

\section{Conclusions}

A semi-analytical effective continuum solution has been developed for steady, one-dimensional vertical flow in unsaturated fractured rock. The solution has been generalized to apply to layered fractured rock, where constitutive relationships and intrinsic properties are employed for the fracture and matrix materials in each layer. The liquid-saturation and pore-velocity distributions are derived for the fractures, matrix, and effective continuum. Examples of the solution are provided for both homogeneous and composite fractured rock domains. Comparisons with numerical simulations demonstrate the accuracy of the semi-analytical solution and the potential benefit of using the analytical solutions as benchmarking tools for testing the adequacy of numerical simulations. Computational issues such as grid refinement and weighting schemes can be addressed through comparisons with the analytical benchmarks, which can help validate and/or build confidence in the more complex numerical models of unsaturated flow in fractured rock.

\section{Acknowledgments}

The author would like to thank Mike Wilson and Erik Webb for their review and thoughtful discussions of this work. Sandia is a multiprogram laboratory operated by Sandia Corporation, a Lockheed Martin Company, for the United States Department of Energy under Contract DEAC04-94AL85000. 


\section{References}

Buscheck, T. A., and J. J. Nitao, Repository-heat-driven hydrothermal flow at yucca mountain, part I: modeling and analysis, Nuclear Technology, 104 (3), 418-448, 1993.

Doughty, C., Investigation of conceptual and numerical approaches for evaluating moisture, gas, chemical, and heat transport in fractured unsaturated rock, J. Cont. Hydrol., 38(1-3), 69-106, 1999.

Eaton, R. R., C. K. Ho, R. J. Glass, R.J., M. J. Nicholl, and B. W. Arnold, Three-Dimensional Modeling of Flow Through Fractured Tuff at Fran Ridge, Rep. SAND95-1896, Sandia Nat. Lab., Albuquerque, N. M., 1996.

Gardner, W. R., Some steady-state solutions of the unsaturated moisture flow equation with application to evaporation from a water table, Soil Sci., 85, 228-232, 1958.

Ho, C.K., S. J. Altman, and B. W. Arnold, Alternative conceptual models and codes for unsaturated flow in fractured tuff: preliminary assessments for GWTT-95. Rep. SAND95-1546, Sandia Nat. Lab., Albuquerque, N. M., 1995.

Klavetter, E. A., and R. R. Peters, Estimation of hydrologic properties of an unsaturated, fractured rock mass, Rep. SAND84-2642, Sandia Nat. Lab., Albuquerque, N. M., 1986.

Liu, H. H., C. Doughty, and G. S. Bodvarsson, An active fracture model for unsaturated flow and transport in fractured rocks, Water Resources Research, 34, 2633-2646, 1998.

Mualem, Y., A new model for predicting the hydraulic conductivity of unsaturated porous media, Water Resour. Res., 12 (3), 513-522, 1976. 
Parlange, J.-Y., D. A. Barry, M. B. Parlange, W. L. Hogarth, R. Haverkamp, P. J. Ross, L. Ling, and T. S. Steenhuis, New approximate analytical technique to solve Richards equation for arbitrary surface boundary conditions, Water Resour. Res., 33(4), 903-906, 1997.

Peters, R.R., and E. A. Klavetter, A continuum model for water movement in an unsaturated fractured rock mass, Water Resources Research, 24 (3), 416-430, 1988.

Pruess, K., TOUGH2 - a general-purpose numerical simulator for multiphase fluid and heat flow, Rep. LBL-29400, Lawrence Berkeley Nat. Lab., Berkeley, CA, 1991.

Pruess, K. (Ed.), Proceedings of the TOUGH workshop '98, Rep. LBNL-41995, Lawrence Berkeley Nat. Lab., Berkeley, CA, 1998.

Pruess, K., and T. N. Narasimhan, A practical method for modeling heat and fluid flow in fractured porous media, Soc., Pet. Eng. J., 25, 14-26, 1985.

Pruess, K., Y. W. Tsang, and J. S. Y. Wang, Modeling of strongly heat driven flow in partially saturated fractured porous media, in Proceedings, IAH $17^{\text {th }}$ International Congress on the Hydrogeology of Rocks of Low Permeability, pp. 486-497, University of Arizona, Tucson, 1985.

Pruess, K., J. S. Y Wang, and Y. W. Tsang, On thermohydrologic conditions near high-level nuclear wastes emplaced in partially saturated fractured tuff. 2 . Effective continuum approximation, Water Resourc. Res., 26(6), 1249-1261, 1990.

Pruess, K., B. Faybishenko, and G. S. Bodvarsson, Alternative concepts and approaches for modeling flow and transport in thick unsaturated zones of fractured rocks, J. Cont. Hydrol., $38(1-3), 281-322,1999$. 
Rockhold, M. L., C. S. Simmons, and M. J. Fayer, An analytical solution technique for onedimensional, steady vertical water flow in layered soils, Water Resour. Res., 33(4), 897-902, 1997.

Tsang, Y. W., and K. Pruess, A study of thermally induced convection near a high-level nuclear waste repository in partially saturated fractured tuff, Water Resources Research, 23 (10) 1958$1966,1987$.

van Genuchten, M.T., A closed-form equation for predicting the hydraulic conductivity of unsaturated soils, Soil Science Society of America Journal, 44 (4), 892-898, 1980.

Warrick, A. W., and T.-C. J. Yeh, One-dimensional, steady vertical flow in a layered soil profile, Adv. Water Resour., 13, 207-210, 1990.

Wu, Y.-S., C. Haukwa, and G. S. Bodvarsson, A site-scale model for fluid and heat flow in the unsaturated zone of Yucca Mountain, Nevada, J. Cont. Hydrol., 38(1-3), 185-215, 1999. 


\section{List of Figures}

Figure 1. Analytical and numerical TOUGH2 results for steady infiltration $(0.1 \mathrm{~mm} / \mathrm{year})$ in a one-dimensional, unsaturated, fractured domain. Three discretizations are used for the TOUGH2 simulations (Note: for the 100 -element simulation, the results for every $5^{\text {th }}$ element are shown).

Figure 2. Analytical solutions for pore velocity in the fracture and matrix for a steady bulk infiltration $(0.1 \mathrm{~mm} / \mathrm{year})$ in a one-dimensional, unsaturated, fractured domain. A log-log scale is used to emphasize the pore velocities at lower elevations.

Figure 3. Analytical and numerical TOUGH 2 results for steady infiltration $(0.1 \mathrm{~mm} /$ year $)$ in a layered, one-dimensional, unsaturated, fractured domain. The same fracture properties are used for all three layers. (Note: only the results from every $5^{\text {th }}$ element of the TOUGH2 model are shown).

Figure 4. Analytical solutions for pore velocity in the fracture and matrix for a steady bulk infiltration $(0.1 \mathrm{~mm} / \mathrm{year})$ in a layered, one-dimensional, unsaturated, fractured domain. 


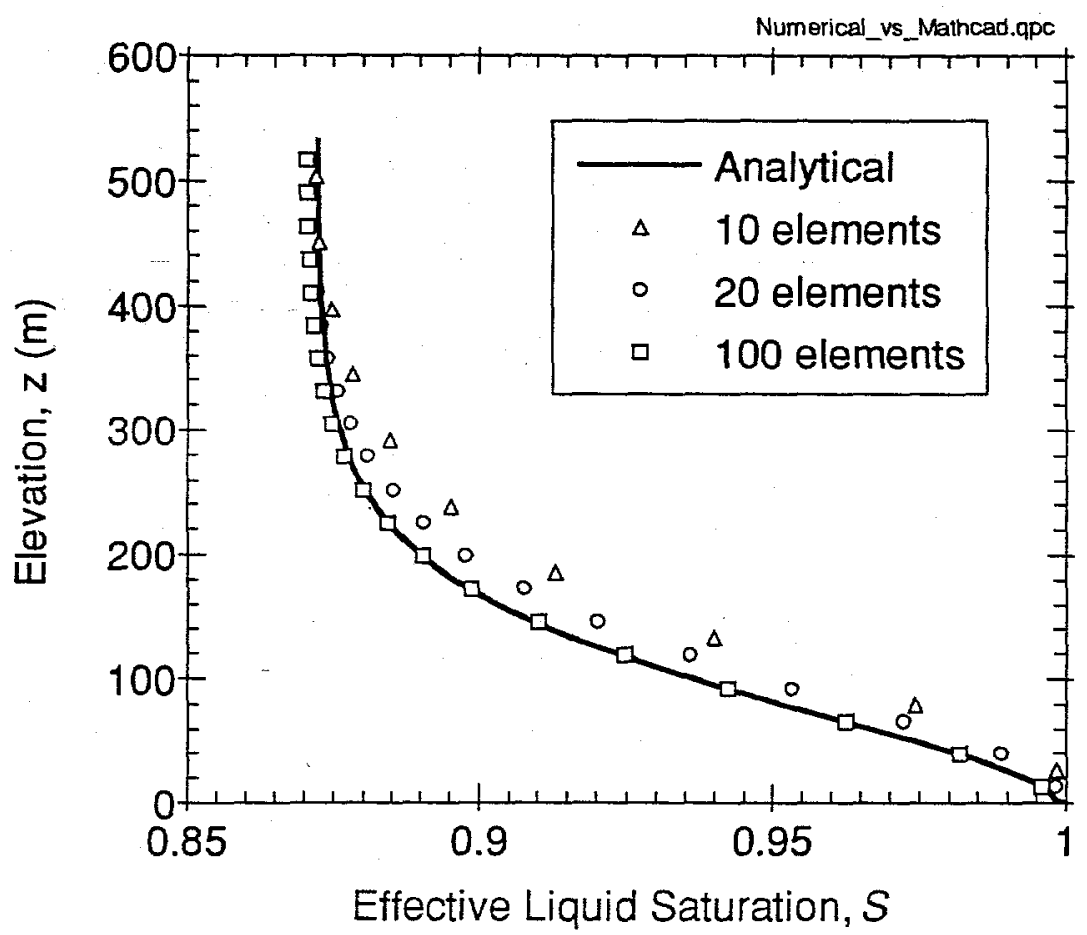

Figure 1. Analytical and numerical TOUGH 2 results for steady infiltration $(0.1 \mathrm{~mm} /$ year $)$ in a one-dimensional, unsaturated, fractured domain. Three discretizations are used for the TOUGH2 simulations (Note: for the 100-element simulation, the results for every $5^{\text {th }}$ element are shown). 


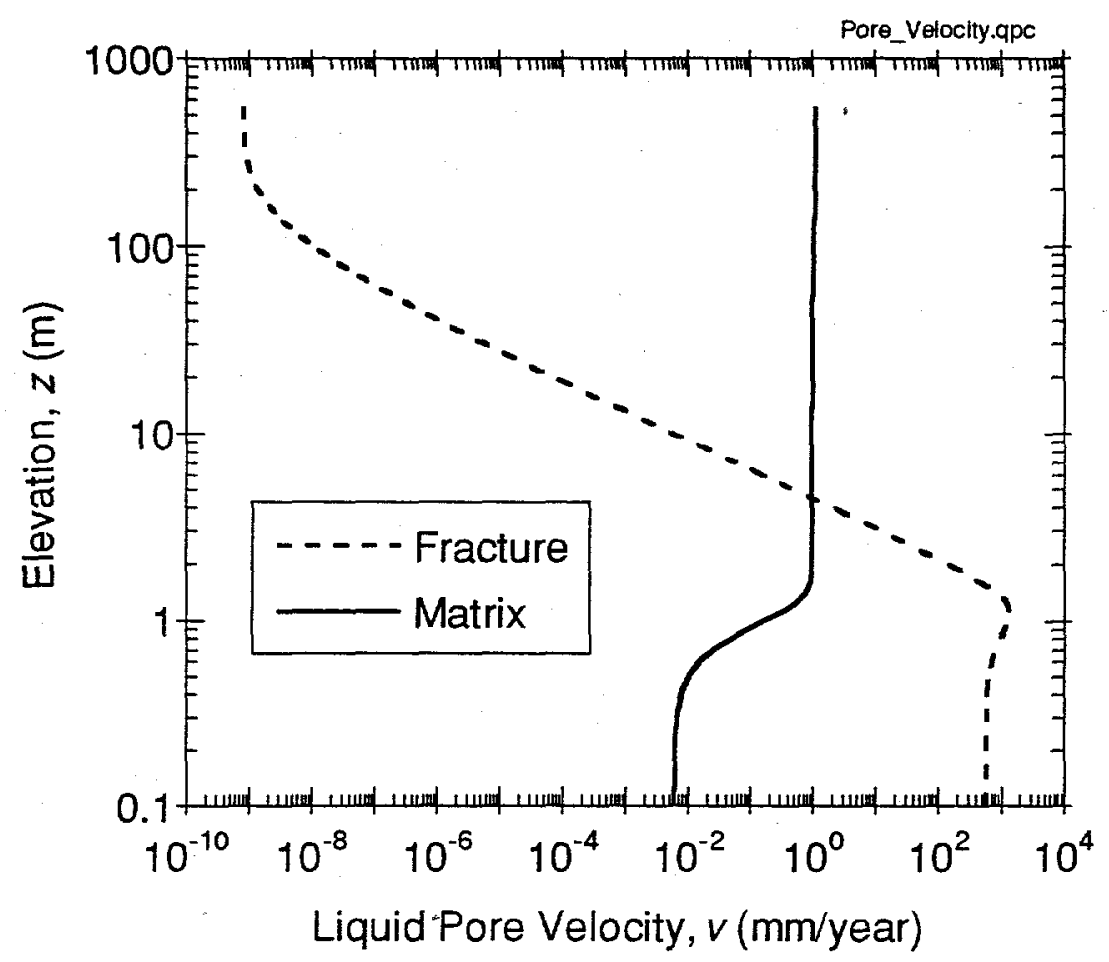

Figure 2. Analytical solutions for pore velocity in the fracture and matrix for a steady bulk infiltration $(0.1 \mathrm{~mm} / \mathrm{year})$ in a one-dimensional, unsaturated, fractured domain. A log-log scale is used to emphasize the pore velocities at lower elevations. 


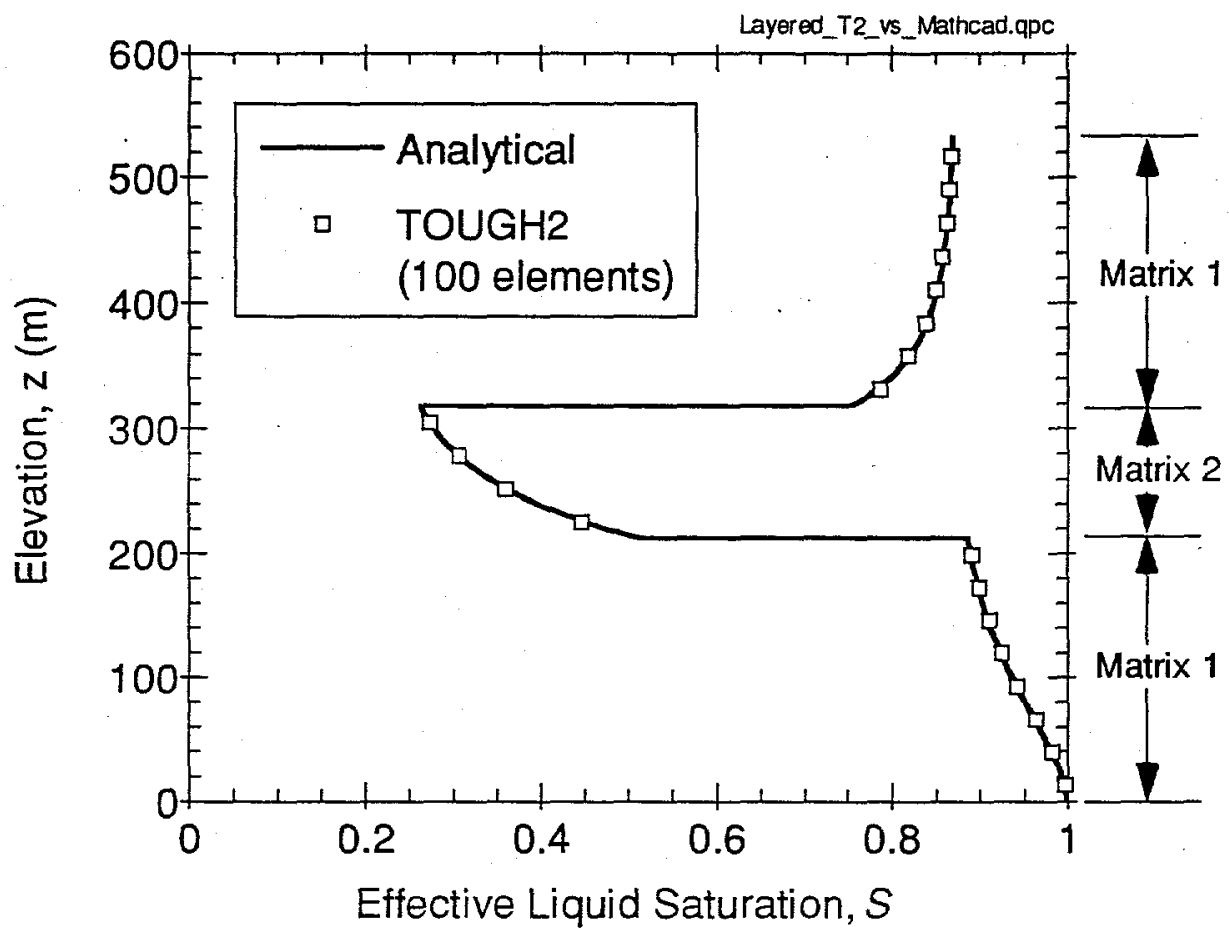

Figure 3. Analytical and numerical TOUGH 2 results for steady infiltration $(0.1 \mathrm{~mm} /$ year $)$ in a layered, one-dimensional, unsaturated, fractured domain. The same fracture properties are used for all three layers. (Note: only the results from every $5^{\text {th }}$ element of the TOUGH2 model are shown). 


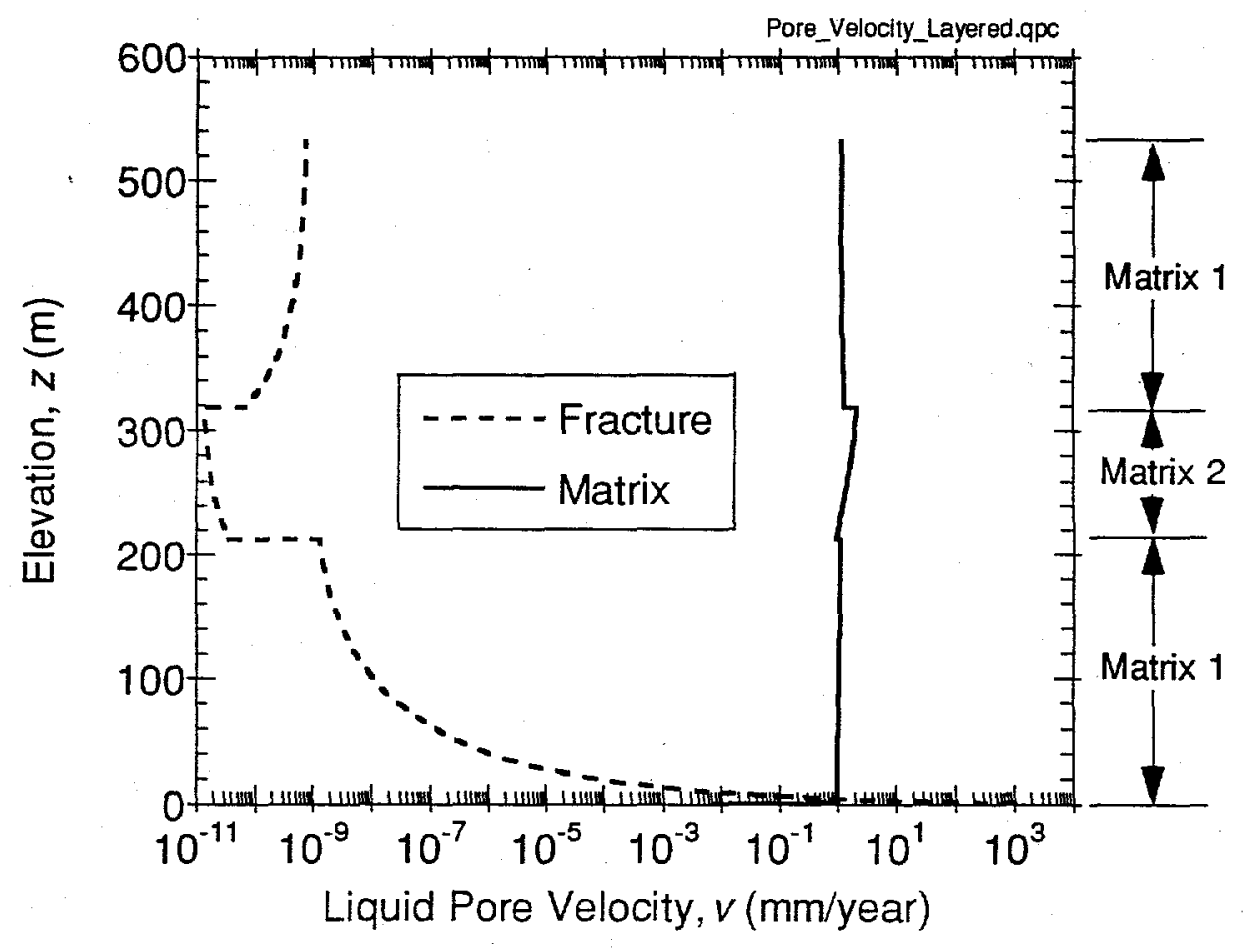

Figure 4. Analytical solutions for pore velocity in the fracture and matrix for a steady bulk infiltration $(0.1 \mathrm{~mm} /$ year $)$ in a layered, one-dimensional, unsaturated, fractured domain. 